\title{
From the New ACM President
}

\section{I thank all of you who recently sent along good wishes upon my election to ACM president. Many also asked "What do you want to accomplish during your presidency?"}

To begin to answer this, I refer back to the recent message from outgoing President Alex Wolf as he looked back on his two years in office (Communications, June 2016 , p. 5). He noted that the foundations of ACM are in excellent shape; we have committed volunteers, dedicated headquarters staff, and a reliable revenue stream. I thank him for his efforts in guiding ACM to this position of strength. My goals are to build on this foundation, being responsive to changing demographics, finding new ways to add value to both our student and professional members, and balancing the desire for open access to our Digital Library with the need to maintain our economic health.

While there are over two million global students and professionals who benefit from our publishing, professional development, education curricula, worldwide conferences, and networking opportunities, most of these individuals do not join ACM. All of our work, however, is only possible through the volunteer efforts and the organizational stability of membership. We need to reconsider the benefits of membership in a professional society. For this, we will be seeking input in the coming months to clarify what our community most values.

One demographic that has been slow to join ACM is early career professionals. I will be spearheading efforts to increase the involvement of this cohort. In rapidly changing academic, entrepreneurial, practitioner, and global computing environments, networking through ACM can provide real value. In the coming months, new initiatives for these young professionals will be formulated and announced.
In terms of publications, I look forward to our Digital Library continuing to evolve. Under the direction of ACM's Publications Board, this community resource will be moving from a static repository of documents and videos to one that includes computing artifacts such as data and software as well as new services. The Digital Library underpins ACM's financial stability but the drive toward open access will continue to challenge assumptions about the exchange of information and data in the scientific community. Questions of how ACM as an academic publisher will derive needed funding in this changing content and services environment will continue to dominate discussions with multiple stakeholders.

In my candidate statement, I mentioned that ACM's efforts related to increased diversity and inclusion need to be fully woven into our core fabric. The re-

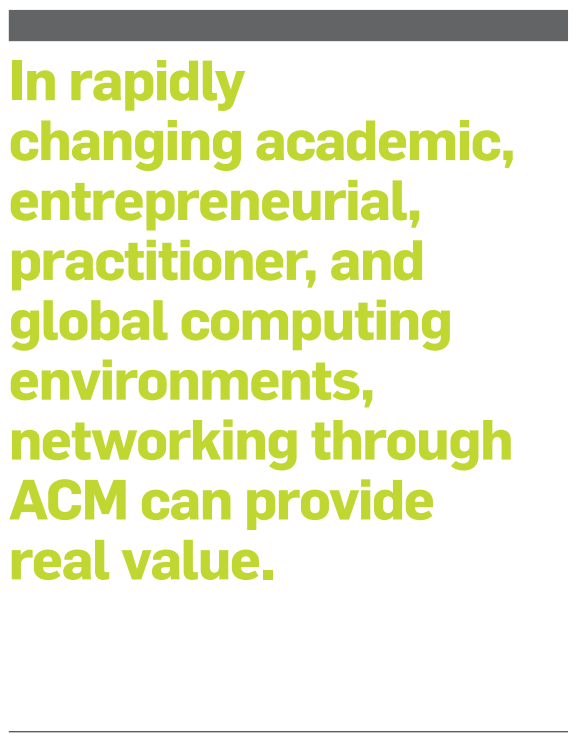

cent election of the first all-female team of ACM Executive Officers is an opportunity to highlight the contributions that women have made to computing and to inspire young women to view computing as a career. While we can be proud of this milestone, we must be mindful that diversity involves many issues and professionals at all career stages. We will expand the scope for our diversity efforts, including accessibility and diversity concerns globally.

ACM must also continue to serve the worldwide computing community in all our activities. Our publishing, professional development, conferences, and other efforts must not just be available to global professionals, but also must take into account varying regional priorities. I am deeply committed to the fostering of this global perspective.

This year marked the 50th anniversary of the ACM A.M. Turing award. We can be deservedly proud of the honorees who have made such profound impacts on technology and society. Throughout the coming year we will be celebrating the achievements of these pioneers. More information on these celebrations will be forthcoming.

In sum, during my presidency I will work to develop new initiatives to ensure that ACM provides ever-greater value to the global computing community. Over the next two years, I look forward to meeting many of you and exploring how, together, we can achieve this.

Vicki L. Hanson (vlh@acm.org) is ACM President, Distinguished Professor at Rochester Institute of

Technology, and a professor at the University of Dundee. Twitter: @ACM_President 